\title{
Representaciones sociales de la "identidad argentina" en la población nativa residente en la Ciudad Autónoma de Buenos Aires ${ }^{1}$
}

\author{
Social representations of the "argentine identity" \\ in the native population resident in the Autonomous City \\ of Buenos Aires
}

Recibido:13 de diciembre de 2016. Revisado: 23 de noviembre de 2017. Aceptado: 19 de diciembre de 2017.

Anahí González ${ }^{2}$
Gisele Kleidermacher ${ }^{3}$

\section{Resumen}

El artículo analiza las representaciones sociales que construyen los residentes de la Ciudad Autónoma de Buenos Aires acerca de los atributos y características culturales que definirían la identidad argentina. Se analizan parte de los resultados de una encuesta realizada en el 2014 donde se caracterizarían atributos principales de los argentinos. Se pretende reflexionar acerca de los procesos de esencialización, calificación, clasificación y jerarquización de situaciones y personas, que todo proceso de construcción de la notridad supone. Entre los principales hallazgos se encuentran que los encuestados se identifican con la categoría denominada representación iconográfica y con la de soberbia/arrogancia. En cuanto a las representaciones positivas, se registraron en las categorías adaptabilidad/ tenacidad, seguido de solidaridad., y finalmente, en relación a los atributos negativos, la soberbia/arrogancia, es considerada como la principal característica.

\section{Palabras clave}

Representaciones sociales, notridad, comunidad nacional, identidad argentina.

\begin{abstract}
The article analyzes the social representations that residents of the Autonomous City of Buenos Aires build about the attributes and cultural characteristics of Argentine identity. To analyze this Argentineans attributes, it was used part of the results of a survey conducted in 2014. It refers to the processes of essentialization, qualification, classification and ranking of situations and people, supposed in any building notoriety process. Among the main findings are the identification of respondents with the category called iconographic representation and with pride/arrogance. On the positive representations side, they were registered in the categories of adaptability/tenacity, followed by solidarity. Finally, in relation to the negative attributes, arrogance is considered as the main characteristic.
\end{abstract}

\section{Keywords}

Social representation, we ness, national community, argentine identity.
La información analizada en el presente artículo ha sido producida en el marco del Proyecto UBACYT titulado: "Los puentes entre el poder judicial, la institución educativa y la sociedad civil ante la diversidad etno-nacional en el AMBA" con sede en el IIGG. Proyecto de Investigación Científica, de Innovación Tecnológica e Interdisciplinarios. Programación Científica 2014-2017, financiado por la Universidad de Buenos Aires, Argentina.

${ }^{2}$ Doctora en Ciencias Sociales, Magíster en Investigación en Ciencias Sociales y licenciada en Sociología de la Universidad de Buenos Aires. Docente de la Facultad de Ciencias Sociales de la Universidad de Buenos Aires, Buenos Aires, Argentina. Sus temas de investigación refieren al acceso a derechos humanos de los migrantes internacionales, representaciones sociales discriminatorias e interculturalidad. Correo electrónico: anahipgonzalez@gmail.com

3 Doctora en Ciencias Sociales y licenciada en Sociología de la Universidad de Buenos Aires, Argentina. Investigadora del CONICET y de la Universidad de Buenos Aires, Buenos Aires, Argentina, donde también se desempeña como docente. Sus líneas de trabajo son: Migraciones africanas subsaharianas, transnacionalismo, representaciones sociales y relaciones interculturales entre nativos y migrantes. Correo electrónico: kleidermacher@gmail.com

Para citar este artículo use: González, A., y Kleidermacher, G. (2018). Representaciones sociales de la "identidad argentina" en la población nativa residente en la Ciudad Autónoma de Buenos Aires. Revista Civilizar, 18(34), 135-148. 


\section{Introducción}

El presente artículo analizará las representaciones sociales que los argentinos (particularmente aquellos que residen en la Ciudad Autónoma de Buenos Aires) construyen acerca de los atributos (individuales y colectivos) y elementos culturales que definirían su identidad como grupo. En este sentido, entendemos a la identidad como una construcción continua y nunca definitiva en la que se intersectan valores, pautas culturales, vivencias compartidas, expectativas a futuro y reinterpretaciones del pasado reciente e histórico. El conjunto de estos elementos identitarios son reinterpretados en el presente, por los miembros del colectivo nacional, constituyendo así un imaginario acerca del "ser nacional" que se naturaliza y se presenta como "evidente". En otros términos, dichas percepciones acerca de la "notridad" "[...] potencian un sentimiento de conexión con otros miembros de la comunidad cuya construcción simbólica depende de, y al mismo tiempo favorece, el desarrollo de una identidad unificadora" (Alexander, 1997, citado en Terrén, 2003, p. 134).

En suma, el problema de investigación a abordar será la construcción de identificaciones que posibilitan el establecimiento de lazos sociales al interior de la comunidad nacional. Para ello, el trabajo se estructura del siguiente modo: primero, presentamos el andamiaje teórico en el cual basamos nuestra investigación, luego la metodología que ha sido utilizada para la construcción de los datos y, finalmente, exponemos los resultados obtenidos tras la aplicación del cuestionario. En relación a este último punto, en primer lugar, analizamos los datos construidos para la primera de las preguntas acerca de las representaciones de la "notridad". Posteriormente, presentamos los resultados vinculados a aspectos positivos y negativos del "ser argentino" para, por último, exponer las conclusiones del trabajo.

\section{Encuadre teórico: representaciones sociales e identidad nacional}

El marco teórico en el cual basamos nuestro estudio es el vinculado a las representaciones sociales. Consideramos que el potencial que la categoría de representación social presenta como herramienta analítica remite a cómo se intersectan los niveles discursivos y representacionales con los comportamientos de los sujetos resultando en su naturalización y, consecuentemente, incuestionable evidencia. Es decir, tal como plantea Pérez Agote (1993).

[...] puede decirse que la eficacia social de las ideas, representaciones y definiciones de la realidad es su capacidad para determinar o influenciar el comportamiento de los actores sociales; esta capacidad depende del mayor o menor grado de evidencia social que alcance, es decir, de su mayor grado de «objetividad social», en el sentido de lo que está socialmente reconocido de forma compartida (p. 8).

El concepto de representación ha sido desarrollado en primer lugar en el ámbito de la sociología. Ha sido Durkheim el que refiriéndose a las mismas como representaciones colectivas las describe como "rea-lidades [que] sostienen con su sustrato íntimas relaciones [y cuya] autonomía no puede ser sino relativa" (Durkheim, 2000, p- 48, citado en PiñeroRamírez, 2008, p.4). En este sentido, desde la perspectiva del sociólogo francés, las representaciones son construcciones que por su carácter de hecho social son una producción diferente a las representaciones que individualmente tiene cada sujeto, "tienen vida propia", independiente de ellos y por tanto son vistas desde esta perspectiva como una imposición.

Ahora bien, estas definiciones son retomadas por diversos autores desde la psicología social (Moscovici, Jodelet, Farr, entre otros) quienes intentaban librarse de esa perspectiva que definían como determinista. De esta manera, cada uno con sus matices recuperan la idea de la representación pero denominándola ahora 
como social en vez de colectiva. En esta reactualización del concepto, entienden que se trata de un conocimiento socialmente compartido que es tanto de naturaleza social como de tipo individual y psicológico. Así se considera que las representaciones sociales pueden ser heterogéneas entre los diversos colectivos como también al interior de cada grupo social y en este sentido, cobra importancia el contexto en que son construidas (Moscovici, 1986).

Particularmente las representaciones sociales que se refieren a la identidad nacional presentan estas características también, es decir, han sido elaboradas colaborativamente al tiempo que para cada sujeto supone una selección individual de elementos pasados y presentes. Es por ello que el contexto como decíamos adquiere relevancia para la interpretación.

Desde una perspectiva sociológica que contemple todas estas dimensiones de análisis, y siguiendo a Berger y Luckmann (2003), consideramos que las representaciones colaboran en la construcción de la "realidad social", es decir, son elaboradas de manera relacional por los sujetos y refieren no solo al presente sino también a lo que las generaciones pasadas han elaborado. Por tanto, a través de la "objetivación" se construye la sociedad, se convierte en una "realidad objetiva". En estos procesos, la socialización primaria y secundaria cumple un rol central ya que la comunicación, mediada por el lenguaje, permite el anclaje y la sedimentación de las significaciones. Así, la realidad cotidiana es constituida por los sujetos de modo intersubjetivo, tipificándose las situaciones y re-creándose así un orden. Esta perspectiva del construccionismo social ha sido central en la asumida para el análisis de los resultados de la encuesta ya que entendemos que las representaciones sociales son construcciones del mundo de la vida cotidiana y que todo conocimiento es histórico y socialmente específico.

En sintonía con ello, debemos decir que el modo cómo ha sido construida la identidad argentina, sobre todo en Buenos Aires, centro de poder económico y político, articula una serie de elementos cuya continuidad puede evidenciarse aún hoy.

El proyecto político económico de las elites dirigentes de fines del siglo XIX, momento en que los diversos territorios americanos comienzan sus procesos de constitución estatal y delimitación de fronteras nacionales, concibieron para Argentina un proyecto en el que la diversidad de la población significaría un problema. Frente a este, la "solución" orquestada para el caso de las comunidades originarias sería fundamentalmente su aniquilamiento físico y cultural. Por otro lado, el fomento de las migraciones por parte del Estado implicaría una relación ambigua con los extranjeros, los cuales eran vistos como aquellos que traerían los beneficios de la civilización y el progreso "moral" y productivo pero también como generadores de conflictos al no ser la inmigración "esperada" por quienes la alentaban.

Según la historiografía argentina, podemos dividir a los ideólogos del mencionado "proyecto civilizador" en dos grupos, el de la "Generación del 37", definido como un movimiento intelectual que enfatizó la importancia de construir la identidad nacional argentina y cuya influencia se desarrolló desde 1837 hasta 1880 . Sus principales representantes fueron: Esteban Echeverría, Domingo Faustino Sarmiento, Juan María Gutiérrez, Vicente Fidel López, José Mármol, Félix Frías y Juan Bautista Alberdi. Con este mismo afán pero enmarcados en lo que se llamó la "Generación del 80" se encuentran autores tales como Miguel Cané, Eduardo Wilde, Lucio Mansilla y Paul Groussac (Terán, 2008).

En este sentido, "tanto para la generación del 37 como para la generación del 80 (delegados locales de la misión civilizatoria del hombre blanco) el desafío era germinar una nación moderna -léase civilizada- en el desierto cultural y geográfico argentino" (Pacecca, 2001, p.-6). Un 
ejemplo paradigmático de estas figuras ha sido Alberdi, quien en sus escritos, consideraba central llevar adelante la importación del "ethos" de un trabajador laborioso a partir del "trasplante migratorio". Es decir, se consideraba que con la llegada de los migrantes europeos podrían imponerse valores como los del orden, limpieza, civilización y riqueza, todos ellos elementos necesarios para la constitución de una nación moderna (Terán, 2008). En este proceso material pero también narrativo iría constituyéndose la comunidad de nacionales, consolidándose los lazos entre quiénes formarían parte del nosotros y quiénes no. En ello radica la "notridad", en el mecanismo por el cual incluimos pero también excluimos. En este sentido,

La «notridad» potencia un sentimiento de conexión con otros miembros de la comunidad cuya construcción simbólica depende de, y al mismo tiempo favorece, el desarrollo de una identidad unificadora. Por eso, la solidaridad que emana del discurso de la sociedad civil tiende a definirse siempre en términos universalizadores (pues sólo así puede generalizarse $\mathrm{y}$ trascender las diferencias, los intereses y compromisos individuales que impulsan fuerzas o instituciones particularizadoras) (Terrén, 2003, p.134).

De este modo, las representaciones sociales que dan soporte a la identidad nacional objetivizan y naturalizan los vínculos entre los nativos pero del mismo modo consolidan las divisiones con quienes no lo son. Por tanto, coincidimos con lo que también plantea Pérez Agote, esto es, que carece de relevancia que las representaciones acerca de la nación sean "ciertas" o no, lo que interesa son los "efectos de realidad" que la misma es plausible de tener, es decir, si tienen suficiente legitimidad para imponerse como "verdad" y cuáles con los mecanismos a partir de los cuales ello es posible. De ello, se desprende una consecuencia metodológica central consistente en que el cientista social debe pasar por un doble momento analítico al estudiar las representaciones sociales:
En primer lugar, un momento fenomenológico en el cual el sociólogo constituye a la representación social y a sus consecuencias en el comportamiento en objeto de análisis; es un momento comprehensivo; el sociólogo penetra en el interior de la definición, en los significados del actor y en sus comportamientos y su sentido. En segundo lugar, un momento genético, en el que el sociólogo se pregunta por la génesis de la representación, por quién la genera y cómo, por cómo se difunde y alcanza el éxito social (...) porque las representaciones sociales no son una emanación del mundo objetivo, sino ideas generadas y aprehendidas en procesos sociales (Pérez Agote, 1993, p.61).

Finalmente, es importante mencionar que el investigador Martín Mora (2002), especializado en el campo de estudios de las representaciones sociales, identifica tres componentes presentes en ellas: la información -suma de conocimientos con que cuenta el grupo acerca de un fenómeno-, el campo de representación -que expresa la organización del conocimiento en forma jerarquizada e ideológica-, y la actitud -dimensión que significa la orientación favorable o desfavorable en relación con el objeto de representación social.

\section{Estrategia metodológica}

Los antecedentes inmediatos de este escrito consisten en una serie de proyectos de investigación UBACyT ${ }^{1}$, en los cuales se abordó la temática de las representaciones sociales desde una perspectiva cualitativa, basada en el análisis de entrevistas y focus group a la institución educativa y al poder judicial. En cambio, en el proyecto -del que se nutre el presente artículo- se ha desarrollado una metodología cuantitativa pero sin abandonar el objetivo de las anteriores investigaciones, esto es acceder a las representaciones sociales, en este caso de la población civil.

Específicamente, en esta investigación, la estrategia metodológica empleada implicó la construcción de un instrumento de registro 
elegido bajo la modalidad de cuestionario conformado por cinco ejes: en el primero de ellos, se propuso analizar las representaciones que la población nativa produce sobre cuatro grupos migrantes: paraguayos, bolivianos, chinos y africanos. En este eje también se preguntó por las representaciones elaboradas por los encuestados acerca de la migración como fenómeno social y las políticas gubernamentales en relación a la misma. Un segundo eje indagó sobre las representaciones de la población nativa acerca de la notridad. Es decir, respecto a las pautas culturales y sociales compartidas, las rememoraciones de experiencias pasadas y presentes, las autopercepciones acerca de la "idiosincrasia" nacional, etc. En suma, se focalizó en indicadores que permitieran identificar lo que, autores como Schutz (1964), definen como los elementos que forman parte del "mundo de la vida cotidiana" y que tienden a favorecer las identificaciones con un "nosotros". El tercer eje del cuestionario indagó acerca de las representaciones que la población produce respecto a la migración africana subsahariana en la Ciudad Autónoma de Buenos Aires. Preguntó por las percepciones e imaginarios construidos sobre el origen de los migrantes, las causas de su migración y la inserción laboral del colectivo entre otros aspectos. Los ejes subsiguientes refirieron a la conformación socio-económica del encuestado, así como la de su familia y su situación laboral actual. Finalmente, se interrogó sobre las actividades recreativas, de ocio y tiempo libre de la población nativa.

En el presente artículo sólo analizaremos el segundo eje mencionado del cuestionario, es decir, aquel que focaliza en la construcción de la notridad.

La encuesta fue aplicada durante el año 2014 a una muestra de 401 casos, constituida por hombres y mujeres de entre 25 y 65 años de edad. Todos ellos son nativos, residentes en la Ciudad Autónoma de Buenos Aires. Se trató de una muestra intencional no probabilística, construida en base a la distribución de clase social en la ciudad. Se determinaron puntos muestra de diez casos por barrio, realizándose bajo el criterio de unir barrios próximos en materia de clase social y también en cercanía geográfica, intentando respetar el peso de los mismos según su participación en la distribución de nativos entre 25 y 65 años. Asimismo, se ha dividido la muestra en tres clases: de servicios, intermedia y trabajadora.

En relación al contenido del cuestionario, el mismo constó no solo de preguntas abiertas y cerradas, sino también de diferentes escalogramas que posibilitaron estandarizar las distintas representaciones sociales acerca de las poblaciones migrantes así como de la identidad nacional.

Para el tratamiento de la información utilizada en el presente trabajo, hemos procedido al cierre de las preguntas agrupándolas en categorías de acuerdo a afinidades temáticas, las cuales fueron orientadas por el marco teórico de la investigación. La información relevada ha sido codificada y procesada de acuerdo a un plan de tabulados orientado por las hipótesis y objetivos de la investigación, utilizando para el procesamiento estadístico el programa SPSS, tratando la información con aplicaciones de estadística descriptiva (porcentajes, promedios, desvíos, etc.).

En relación a los resultados, nos propusimos analizar los datos producidos a partir de la encuesta en relación a la construcción de representaciones sociales sobre la "notridad", entendida como las representaciones sociales de argentinos acerca de su identidad y la construcción de identificaciones que posibilitan el establecimiento de lazos sociales. Se preguntó por lo que nos caracteriza a los argentinos, así como también lo mejor y lo peor que poseemos como colectivo, todo ello a partir de la elección espontánea de una palabra. Las respuestas fueron agrupadas en categorías por afinidad temática. Los resultados muestran entonces la pertenencia a una comunidad nacional que continúa siendo efectiva en la estructuración de la construcción identitaria. 


\section{Resultados de investigación}

\section{La re-construcción de identificacio- nes nacionales.}

A partir del cierre de las preguntas del cuestionario que forman parte del eje sobre la notridad, aplicado de acuerdo a las pautas relatadas en el anterior apartado, presentamos los principales resultados de investigación. Los mismos refieren a la dimensión acerca las representaciones sociales de los encuestados sobre el "ser nacional", en términos de Terán (2008), remiten al "nacionalismo culturalista", es decir, aquel que se vincula con pautas culturales y la re-construcción cotidiana de un pasado y futuro compartido por los miembros de la comunidad nacional.

El primer interrogante de este eje preguntaba: "Si tuviera que decir cuál es la característica principal de ser argentino, lo que nos identifica como país ¿Qué diría?”. Al tratarse de una pregunta abierta, hemos agrupado en diversas categorías las repuestas obtenidas, las cuales son presentadas en frecuencias porcentuales en el cuadro a continuación.

Cuadro No. 1

Representaciones sociales del "ser argentino". Población Nativa, 25 a 65 años. CABA, 2014

\begin{tabular}{|l|c|}
\hline \multicolumn{1}{|c|}{ Representación } & $\%$ \\
\hline Representación iconográfica & 18 \\
\hline Soberbia/arrogancia & 17,5 \\
\hline Ventajista/"chanta" & 13,2 \\
\hline Solidaridad & 12,2 \\
\hline Adaptabilidad/tenacidad & 8,5 \\
\hline Familieros/amigueros & 8 \\
\hline Sensibilidad & 6,7 \\
\hline Receptivos a la migración & 5,7 \\
\hline Individualismo & 2,5 \\
\hline Otros & 5 \\
\hline No sabe/No contesta & 2,7 \\
\hline Total & 100 \\
\hline
\end{tabular}

Fuente: Elaboración propia en base a Proyecto UBACyT, 2014.
Analizando el cuadro 1 podemos observar que la mayor cantidad de frecuencias porcentuales se concentran en la categoría que hemos denominado representación iconográfica (18\%). Bajo esta nomenclatura hemos agrupado aquellas respuestas que aludían a aspectos vinculados a imágenes, objetos y actividades que son considerados popularmente como representativos de la "argentinidad", entre las respuestas podemos mencionar el mate, el fútbol y la carne. Estas contestaciones consideramos que son neutras, en el sentido que no expresan una valoración positiva o negativa, sino que simplemente dan cuenta de un imaginario común, una serie de gustos y actividades que compartirían los argentinos vistos en un conjunto imaginado. Nos referimos en este caso a una identidad nacional y no solamente a la población "porteña", es decir, residente en la ciudad portuaria y capital del país, ya que se trata de comidas y actividades con las que se identifica toda la población y que no hacen referencia a un espacio específico del país, sino que son compartidas por todos los argentinos.

Se trata de lo que Terán (2008) denomina “el nacionalismo culturalista", en sus palabras “[...] el nacionalismo culturalista dice que ser argentino o lo que fuere es identificarse con un conjunto de pautas culturales (tales como la lengua, ciertos símbolos, usos y costumbres presentes y pasados, cierto <<tipo nacional $>>$ " (p. 121). Se trata de elementos y símbolos que reafirman la pertenencia a un grupo mayor, en este caso, el ser argentino. En la misma línea, Anderson (1993) postula que la nación constituye,

Una comunidad política imaginada porque aun los miembros de la nación más pequeña no conocerán jamás a la mayoría de sus compatriotas, no los verán ni oirán siquiera hablar de ellos, pero en la mente de cada uno vive la imagen de su comunión (p. 23).

En las representaciones sociales de los encuestados parece entreverse un lazo común invisible que recorre a la población de origen 
argentino y sería este el que hace compartir gustos, especialmente culinarios y recreativos, que los aúna en un grupo con características comunes, y que los diferenciaría de aquellos que no forman parte del mismo. Como ya lo observara Hall (1996):

La identificación se construye sobre la base del reconocimiento de algún origen común o unas características compartidas con otra persona o grupo o con un ideal, y con el vallado natural de la solidaridad y la lealtad establecidas sobre este fundamento (p. 10).

Con un porcentaje muy similar $(17,5$ $\%)$ se concentran las respuestas que hicieron alusión al carácter soberbio o arrogante que tendrían los argentinos. Consideramos que se trata de una característica que se construye en respuesta a cómo son caracterizados los argentinos en el exterior. Pero que, si bien solo lo planteamos a modo de hipótesis para seguir profundizando en otros trabajos, se trata de una característica vinculada a los orígenes españoles e italianos que supuestamente tendrían la gran mayoría de los argentinos, en concordancia con el mito de "ser una nación que desciende de los barcos".

Planteamos entonces que la representación del ser soberbio/arrogante se vincula al imaginario construido acerca de la "creencia de la excepcionalidad argentina", compuesto por una población mayoritariamente europea, presente en los discursos de la época de construcción del Estado nacional tales como el de Alberdi y Sarmiento. En este período, las migraciones cumplieron una función primordial, como mencionara Pellegrino (2000), el propósito principal y explícito de los gobernantes argentinos no era solamente el de "poblar el desierto", sino también el de modificar sustancialmente la composición de su población, sumando a los habitantes nativos, inmigrantes europeos, que debían transmitir sus valores al conjunto del país, principalmente hábitos de orden, de industria, de laboriosidad y buena educación.
Estas creencias consideramos que dan origen a las auto-representaciones de los argentinos como una "población superior" al del resto de los países latinoamericanos, dada su mayoritaria "imaginada" blanquedad ${ }^{2}$.

Con un porcentaje del $13,2 \%$, se encuentran agrupadas las respuestas en la categoría ventajista/"chanta", bajo este nombre concentramos aquellas palabras que hacen alusión a una supuesta característica que definiría al "ser" argentino, signado por una actitud que suele adscribirse a la población que vive en Buenos Aires y que consiste en lo que algunas personas denominan "viveza criolla", es decir, conseguir aquello que se desea de una forma facilista, que no requiere mucho esfuerzo. Pero también la palabra chanta hace referencia a aquella persona "que presume de tener algo, especialmente una capacidad, un conocimiento o un poder, que en realidad no posee" ${ }^{3} \mathrm{y}$ esta es una característica que suele atribuirse a -pero de la que también hacen gala- los porteños ${ }^{4}$.

La categoría solidaridad concentra un $12,2 \%$ de las respuestas reforzando esta idea de constituir una comunidad, a la que referimos anteriormente en el sentido planteado por Anderson(1993). De esta forma, el hecho de estar enlazados por relaciones imaginarias fundadas en la pertenencia a un territorio común, es lo que ayudaría explicarla. Esta representación guarda relación con la construcción que los medios masivos de comunicación han hecho de una "Argentina solidaria" reflejada en campañas para reunir fondos que apelan al "espíritu solidario del argentino"s.

La categoría adaptabilidad/tenacidad contiene el 8,5\% de las respuestas. La misma ha sido referida, en la mayoría de los casos, a la capacidad que tendrían los argentinos para salir adelante en momentos de crisis, estando sobre todo muy presente en el imaginario la crisis económico-político-social del año $2001^{6}$. 
Finalmente, con un $8 \%$ de respuestas se encuentra la categoría familieros/amigueros también en una referencia a la sociabilidad que caracterizaría a la mayoría de los argentinos, y decreciendo en orden de concentración de frecuencias porcentuales se encuentran las categorías sensibilidad con un $6,7 \%$ de respuestas, seguido por receptivos a la migración con 5,7\%. Nos interesa resaltar esta última representación, entendiendo que la misma guardaría relación con la construcción de la identidad nacional argentina.

De acuerdo a los estudios realizados por Sergio Caggiano (2005), los proyectos de la generación del 37 y más tarde los de la del $80^{7}$, postulaban que la Argentina debía ser una nación abierta a la inmigración, tal como ha sido plasmado en el preámbulo de la Constitución Nacional de 1853. Este mito estuvo asociado a otro, el de la integración. Es decir, se trataba de una política no solo pro inmigratoria sino también de integración de esa inmigración, con un gran sesgo asimilacionista. Esta idea persiste en el imaginario actual en relación a las nuevas corrientes migratorias en un $5,7 \%$ de las respuestas.

Con el objetivo de profundizar aún más en el análisis de las representaciones sociales que los argentinos construyen sobre sí mismos, distinguiremos a continuación entre aquellas que refieren a atributos positivos y negativos. Esto porque en los procesos de construcción de representaciones sociales se intersectan imágenes arraigadas pasadas y actualizadas cotidianamente que, de este modo, reproducen ideas y percepciones acerca de la(s) identidad(es). En este sentido, al intentar aprehender las representaciones que los argentinos elaboran acerca de "sí mismos" nos acercamos a aquello que Hobsbawn plantea, es decir que, si bien las naciones son una construcción "desde arriba”, -ya que son un producto histórico creado por los Estados modernos-, no pueden entenderse si no se los estudia "desde abajo" o, en los palabras del autor citado "en términos de los supuestos, las esperanzas, las necesidades, los anhelos y los intereses de las personas normales y corrientes [...]" (Hobsbawn, 2004, p.18).

Ahora bien, como veremos en los resultados de la encuesta, este proceso de construcción de representaciones está plagado de "recuerdos" y de "olvidos" (Vernik, 2004). Asimismo, se esencializan las similitudes que permiten que sea pensable un "nosotros" homogéneo con un pasado, un presente y un futuro posible en tanto miembros de una misma comunidad nacional, que se presenta como dada, existente "desde siempre" y "para siempre" $\mathrm{y}$, por tanto, incuestionada e incuestionable. Sin duda, es la clásica definición de Anderson (1993) la que resume de modo acabado todos los elementos de la idea de Nación, es decir, "[...] una comunidad política imaginada como inherentemente limitada y soberana" (p. 23). Es imaginada porque en la mente de cada uno persiste la imagen de la comunión entre sujetos que nunca se conocerán todos entre sí. Es limitada, en tanto tiene fronteras finitas, aunque elásticas, es decir, "[...] ninguna nación se imagina con las dimensiones de la humanidad" (p. 23). Es soberana, porque se basa en un Estado soberano nacido en la época en que la revolución ilustrada echó por tierra la legitimidad del "reino dinástico jerárquico divinamente ordenado". Es una comunidad porque se concibe como un “compañerismo profundo, horizontal" más allá, y a pesar, de las desigualdades que pudieran existir. En este sentido, es que fue pensable para los encuestados responder a preguntas que refieren a las características que definirían a un colectivo tan heterogéneo como lo es cualquier conjunto nacional.

\section{Representaciones positivas}

Presentamos a continuación la distribución de frecuencias porcentuales en relación a las representaciones positivas del "ser argentino" que pueden evidenciarse en las opiniones de los participantes de la investigación. 
Cuadro No. 2

Representaciones positivas del "ser argentino". Población nativa, 25 a 65 años. CABA, 2014

\begin{tabular}{|l|c|}
\hline \multicolumn{1}{|c|}{ Representación } & $\%$ \\
\hline Adaptabilidad/tenacidad & 30,7 \\
\hline Solidaridad & 24,7 \\
\hline Familieros/amigueros & 7 \\
\hline Receptivos a la otredad & 6,5 \\
\hline Cálidos/simpáticos & 6,2 \\
\hline Representación iconográfica & 4,5 \\
\hline Apasionados & 3,5 \\
\hline Nacionalistas/patriotas & 2,7 \\
\hline Inteligentes/cultos & 2,5 \\
\hline Ventajista/"chanta" & 1,2 \\
\hline Otros & 7 \\
\hline No Sabe/No contesta & 3,5 \\
\hline Total & 100 \\
\hline
\end{tabular}

Fuente: Elaboración propia en base a Proyecto UBACyT, 2014.

Como puede observarse en el cuadro 2, la representación con mayor porcentaje es aquella que refiere a la adaptabilidad/ tenacidad de los argentinos. Así, el 30,7\% de los encuestados manifestaron que dicho atributo, de carácter positivo, se vincula fundamentalmente con las crisis económicas y políticas que ha atravesado el país a lo largo de su historia. En este sentido, dicha representación se arraiga en un pasado común histórico antiguo y reciente por el que todos "nosotros" hemos transitado y logrado superar. Este tipo de construcción de la identidad remite entonces a un pasado compartido. No obstante, no excluye a la idea de futuro o, en términos de Vernik (2004) futuridad, ya que supone -desde la perspectiva de quienes elaboran esta representación- la posibilidad de "encontrarnos" en eventuales crisis por venir con la misma fortaleza, capacidad de adaptación y cambio que permitan sortear los obstáculos.

Por otra parte, a la representación que refiere a la adaptabilidad/tenacidad, le sigue en orden de importancia numérica la idea de la solidaridad. En esta categoría (que reúne el 24,7\% de las opiniones dadas) incluimos las respuestas que referían a que los argentinos son buenos, generosos, bondadosos. Sobre este imaginario de la "solidaridad argentina" ya hemos dicho lo suficiente en el apartado anterior, solo recordar que remite a la idea de la constitución de lazos dentro de la comunidad nacional construida históricamente y más recientemente a la concepción caritativa alimentada por los medios masivos de comunicación.

Asimismo, las respuestas que concentran los menores porcentajes son ventajista/ "chantas" con un $1,2 \%$, lo cual resulta lógico debido a que la pregunta refería a atributos positivos que definieran a los argentinos. Enseguida, con un 2,5\% y $2,7 \%$, le siguen la opinión acerca de que los argentinos son inteligentes/cultos y nacionalista/ patriotas, respectivamente. Resulta interesante resaltar que una de las respuestas con menor porcentaje sea la que refiere al patriotismo y/o nacionalismo. Diversos autores han planteado ya la importancia de los procesos de nacionalización de las sociedades a partir de las conformaciones de los estados modernos y el rol que las instituciones han cumplido en la generación de aquel sentimiento. Así, Balibar (1988) plantea que la identidad nacional o el nacionalismo presume la presencia de dos temas ideológicos: "la etnicidad ficticia" y el "patriotismo". La primera, remite a la creación simbólica de una base étnica "pura", que no existe en la realidad, y que excluye a aquellos que "no los posean", al tiempo que el patriotismo remite a la nación como comunidad trascendente, con una misión y destino común. No obstante, como señalamos, los encuestados la mencionan entre una de las características positivas que menos atribuirían a los argentinos. En suma, en sus opiniones, verbalizan tipificaciones que elaboran a partir de sus acervos de "conocimiento de la vida cotidiana". En este sentido, construyen "esquemas típicos de los motivos y fines de los actores e incluso de sus actitudes y personalidades" (Schutz y Luckmann, 2001, p. 81). 


\section{Representaciones negativas}

Analicemos ahora aquellas características que se vinculan con representaciones negativas del "ser argentino".

\section{Cuadro No. 3}

Representaciones negativas del "ser argentino". Población nativa, 25 a 65 años.

\begin{tabular}{|l|c|}
\hline \multicolumn{1}{|c|}{ Representaciones } & $\%$ \\
\hline Soberbia/arrogancia & 37,4 \\
\hline Individualismo & 10,7 \\
\hline Ventajista/"chanta" & 10 \\
\hline Corrupción/transgresiones de normas & 8,7 \\
\hline Vagos & 6,2 \\
\hline Pasivos/ingenuos & 3,7 \\
\hline Quejosos & 3,5 \\
\hline Falta de patriotismo & 3 \\
\hline Discriminadores & 2,4 \\
\hline Receptivos a la migración & 2,2 \\
\hline Falta de memoria & 1,5 \\
\hline Violentos & 1,5 \\
\hline Otros & 7 \\
\hline No sabe/no contesta & 2,2 \\
\hline Total & 100 \\
\hline
\end{tabular}

Fuente: Elaboración propia en base a Proyecto UBACyT, 2014.

En relación a las características negativas que los encuestados le atribuyen a los argentinos, puede verse, en el cuadro 3, que la opción soberbia/arrogancia se presenta, como la de mayor porcentaje, un $37,4 \%$, con una marcada distancia en relación a la segunda y tercera opinión más mencionada: individualismo $(10,7 \%)$ y ventajista/"chanta" (10\%).

Aquella autopercepción (soberbia/arrogancia) se vincula con el lugar que las clases dirigentes, que inicialmente asumieron la labor de constituir la nación, le otorgaron al país dentro de la región. Argentina sería desde su perspectiva "una porción de Europa en América". Dicha idea se articulaba con la "importación" de población de dicho continente. Esta visión del proceso de europeización que debía realizarse a fines del siglo XIX y comienzos del XX, colocando claro está a los territorios transoceánicos $\mathrm{y}$ a sus habitantes como referentes positivos y factores que mejorarían a los miembros de la sociedad local, ha persistido aun hoy, reconfigurándose-como ya hemos dicho- en aquella idea de que "los argentinos descendemos todos de los barcos" y, por tanto, ocuparíamos un lugar diferencialmente superior en relación a otros países del subcontinente.

Asimismo, las características con menor presencia es la de violentos y falta de memoria, ambos con un $1,5 \%$. Otro dato a destacar es que la segunda opción con mayor frecuencia mencionada - aunque se encuentra a más de 27 puntos porcentuales de la primera de las respuestas- sea: individualistas, si tenemos en consideración que, entre las representaciones positivas más nombradas, la de la solidaridad ocupaba también el segundo puesto. No obstante, tal como se ha dicho ya hace tiempo: "el conocimiento del hombre que actúa y piensa dentro del mundo de su vida cotidiana no es homogéneo; es 1) incoherente, 2) solo parcialmente claro, y 3) en modo alguno exento de contradicciones" (Schutz, 1964, p. 97).

Empero, las representaciones sociales suponen la calificación y clasificación de los sujetos. Ello queda evidenciado en las respuestas dadas por los encuestados. Por ejemplo, es en la autodefinición de los argentinos como, fundamentalmente, soberbios arrogantes, que se plasma un modo de percibir a la notridad. De esta manera, se construye una determinada $m i$ rada (en este caso autoreferencial) cargada de sentidos y símbolos.

\section{Conclusiones}

Consideramos que las representaciones sociales sobre la "identidad nacional" se apoyan en una serie de elementos comunes, en donde se intersectan fragmentos del pasado, del presente y del futuro, ya que consideramos las identida- 
des como procesos cambiantes y no estáticos. De esta forma, la doble ilusión de la identidad nacional remite a la idea de "proyecto" y de "destino" que compartirían todos los miembros de la comunidad nacional (Balibar, 2005).

Para analizar entonces la construcción de relaciones sociales al interior de la población, resulta pertinente como herramienta de análisis la categoría de representaciones sociales; su potencialidad se basa en vincular los imaginarios sociales con las prácticas, aunque no suceda esto de una manera mecánica.

En otros términos, la información acerca de quiénes somos, construida grupalmente, se configura en un campo de representación, de manera ordenada, jerarquizada, que califica y clasifica a la "notridad" y a la "otredad". De esta forma, se tornan pensables y analizables ciertas conductas y la producción de determinadas relaciones sociales.

El objetivo del artículo ha sido abordar la cuestión de las representaciones sociales acerca de la identidad y/o identificaciones de los argentinos con el fin de contribuir en la comprensión de los procesos que nos constituyen como sujetos. Es decir, en tanto la identidad se encuentra constituida de representaciones del "nosotros" o, más bien, de lo que es "nuestro" en relación a lo que es de los "otros" consideramos que indagar, como lo hemos hecho en este artículo, acerca de los imaginarios de la notridad nacional es un significativo aporte para el estudio de los modos como los sujetos constituimos y reconstituimos cotidiana e históricamente nuestros vínculos y relaciones sociales.

En relación a la construcción de la "identidad nacional", la mayor cantidad de respuestas se concentraron en la categoría construida y denominada representación iconográfica y en segundo lugar, soberbia/arrogancia. Consideramos que la representación iconográfica es un proceso de construcción de representaciones plagado de recuerdos y olvidos, vinculado al llamado "nacionalismo culturalista", donde se conjugan elementos culturales propios de una "Argentinidad" construida sobre la base de un pasado y futuro que se autoperciben como compartidos. De esta manera, se esencializan las similitudes que permiten que sea pensable un "nosotros" homogéneo, con un pasado, presente y futuro posible en tanto miembros de una comunidad nacional presentada como "dada desde siempre" y "para siempre".

En cuanto a las representaciones positivas, los mayores porcentajes se registraron en las categorías adaptabilidad/tenacidad, seguido de solidaridad. La primera hace también referencia a un pasado común histórico, antiguo y reciente, que todos como argentinos hemos logrado superar, el segundo, a la comunión que genera el ser parte de un "nosotros". Nuevamente se observa la construcción de una identidad sobre la base de un pasado y un futuro comunes, elemento fundamental para la construcción de las representaciones sociales.

En cuanto a los atributos negativos, los mayormente mencionados han sido soberbia/ arrogancia, también considerado como principal característica de los argentinos. En segundo lugar se concentran las respuestas en individualismo (10,7\%), lo cual es llamativo, teniendo en cuenta que solidaridad fue representado en un 24,7\% como atributo positivo.

Las características mencionadas, tanto positivas como negativas, guardan correspondencia con la construcción histórica que se ha formado y transmitido a través de instituciones formales y medios masivos de comunicación, a lo largo de generaciones. Desde la construcción de un relato de la formación nacional hasta la actualidad, con leves modificaciones, se han producido representaciones sociales que unen al ser argentino con la migración europea producida entre la última mitad del siglo XIX y comienzos del XX.

Aquella migración deseada, que traería pujanza y modernización. Ese "crisol” constitui- 
do por italianos y españoles fundamentalmente, y establecido sobre todo en la zona portuaria de Buenos Aires, es la síntesis representacional del "ser argentino". En ella confluyen representaciones iconográficas como el fútbol, el tango o el mate, pero también la arrogancia de aquel habitante de la capital del país, quien lucha contra la adversidad, pasada y presente, de los males económicos que han aquejado al territorio, pero que gracias a su tenacidad sale airoso.

Nos proponemos en futuras indagaciones profundizar en el análisis de las representaciones que se producen en la población que habita el Gran Buenos Aires, es decir, aquellos habitantes de los cordones suburbanos, donde se configuraron trayectorias y construcciones identitarias con características propias. Entendemos que ello posibilitará realizar un análisis comparativo entre regiones así como avanzar en la aprehensión y el estudio de un fenómeno sumamente amplio, cambiante y profuso como el de la constitución de la(s) identidad (es).

\section{Notas}

${ }^{1}$ Proyectos de investigación acreditados y financiados por la Universidad de Buenos Aires.

2 Ver Crosa Portilli, Silberstein, y Tavernelli. (2009).

3 Diccionario de la Real Academia Española. http://dle.rae.es/

${ }^{4} \mathrm{Si}$ bien este término se utiliza para aludir a aquella persona que vive en una ciudad que tiene puerto, en el caso de la Argentina hace referencia a aquellos que viven en la ciudad portuaria de Buenos Aires.

${ }^{5}$ A modo de ejemplo en esta nota puede observarse en el periódico de mayor tirada nacional notas referidas al tema http://muy. clarin.com/opinion/litoral-inundacionessolidaridad-argentina-7839.html.
${ }^{6}$ La crisis de diciembre de 2001 en Argentina, o crisis de 2001, también referida como el Cacerolazo o el Argentinazo, fue una crisis política, económica, social e institucional, potenciada por una revuelta popular generalizada bajo el lema "¡Qué se vayan todos!", que causó la renuncia del entonces presidente de Argentina Fernando de la Rúa, dando lugar a un período de inestabilidad política durante el cual cinco funcionarios ejercieron la presidencia de la nación. Sucedió en el marco de una crisis mayor que se extendió entre 1998 y 2002, causada por una larga recesión que disparó una crisis humanitaria, de representatividad, social, económica, financiera y política (Telchea, 2006).

7 El desencadenante inmediato de la crisis fue la imposición del "Corralito", una disposición del Gobierno que restringía la extracción de dinero en efectivo de los bancos, diseñada por el entonces ministro de economía Domingo Cavallo. La revuelta se generalizó el 19 de diciembre de 2001, inmediatamente después de que el presidente radical, Fernando de la Rúa, anunciara el establecimiento del estado de sitio, causando su renuncia al día siguiente. La mayor parte de las personas que participaron en las protestas fueron autoconvocadas y no respondían a ningún partido político, sindicato u organización social estructurada.

\section{Referencias}

Anderson, B. (1993). Comunidades imaginadas. Reflexiones sobre el origen y la difusión del nacionalismo. México: Fondo de Cultura Económica.

Balibar, E. (1988). La forma nación: historia e ideología. En E. Balibar, e I. Wallerstein (Eds.), Raza, Nación y Clase (pp. 135167). Madrid: IEPALA.

Balibar, E. (2005). Violencias, identidades y civilidad. Barcelona: Gedisa. 
Berger, P. y Luckmann, T. (2003). La construcción social de la realidad. Buenos Aires: Amorrortu

Caggiano, S. (2005). Lo que no entra en el crisol. Inmigración boliviana, comunicación intercultural y procesos identitarios. Buenos Aires: Prometeo Libros.

Crosa Portilli, J., Silberstein, Y. y Tavernelli, R. (2009). De la jerarquización de naciones a la clasificación de sujetos: representaciones que perpetúan un orden exclusor. En N. Cohen (Comp.), Representaciones de la diversidad: trabajo, escuela y juventud. Buenos Aires: Ediciones Cooperativas.

Hall, S. (1996). ¿Quién necesita identidad? En S. Hall y P. du Gay (Comps.), Cuestiones de identidad cultural (pp. 1-39). Buenos Aires: Amorrortu.

Hobsbawm, E. (2004). Naciones y nacionalismo desde 1780. Barcelona, España: Crítica.

Mora, M. (2002). La teoría de las representaciones sociales de Serge Moscovici. Revista Athenea Digital, (2), 1-25.

Moscovici, S. (1986). Psicología social. Barcelona: Paidós.

Pacecca, M. I. (2001). Migrantes de ultramar, migrantes limitrofes. Políticas migratorias y procesos clasificatorios. Argentina, 1945-1970. Buenos Aires: CLACSO.

Pellegrino, A. (2000). Migrantes latinoamericanos, síntesis histórica y tendencias recientes. Montevideo: Universidad de la
República; CELADE (Centro Latinoamericano y Caribeño de Demografía).

Pérez Agote, A. (1993). Las paradojas de la nación. REIS, (61), 7-21.

Piñero-Ramírez, S. L. (2008). La teoría de las representaciones sociales y la perspectiva de Pierre Bourdieu: Una articulación conceptual. CPU-e, Revista de Investigación Educativa, (7). Recuperado de http://www.uv.mx/cpue/num7/inves/ pinero_representaciones_bourdieu.html

Schutz, A. (1964). Sobre el extranjero. En A. Schütz (Ed.), Escritos II (pp. 95-107). Buenos Aires: Amorrortu.

Schutz, A., y Luckmann, T. (2001). Las estructuras del mundo de la vida. Buenos Aires: Amorrortu.

Telechea, R. (2006). Historia de los cacerolazos: 1982-2001. Razón y revolución, (16). 141-184

Terán, O. (2008). Historia de la ideas en la Argentina. Diez lecciones iniciales, 1810 1980. Buenos Aires: Siglo XIX.

Terrén, E. (2003). La ironía de la solidaridad: cultura, sociedad civil y discursos sobre el conflicto racial de El Ejido. REIS, (102), 125-146.

Vernik, E. (2004). Qué es una Nación. La pregunta de Renán revisitada. Buenos Aires: Prometeo. 
